\title{
Nutritional status of indigenous children younger than five years of age in Mexico: Results of a National Probabilistic Survey
}

Juan A Rivera, MS, PhD, (1) Eric A Monter rubio, Lic Inf, ${ }^{(1)}$ Teresa González-C ossío, MS, PhD, (1) Raquel García-Feregrino, BSc, ${ }^{(1)}$ Armando García-Guerra, MSc, ${ }^{(1)}$ Jaime Sepúlveda-Amor, MD, ScD. ${ }^{(2)}$

\begin{abstract}
Rivera JA, Monterrubio EA, González-CossíoT, García-Feregrino R, García-Guerra A, Sepúlveda-Amor J. Nutritional status of indigenous children younger than five years of age in Mexico: Results of a National Probabilistic Survey. Salud Publica Mex 2003;45 suppl 4:S466-S476. The English version of this paper is available too at: http://www.insp.mx/salud/index.html
\end{abstract}

\begin{abstract}
A bstract
Objective To compare the prevalence of undernutrition and anemia in indigenous and non-indigenous children $<5$ years of age at the national level, by region and by urban and rural areas, and to evaluate the degree to which the socioeconomic condition of the family predicts the differences. Material and Methods. A national probabilistic survey was conducted in Mexico in 1999. Indigeno us families were identified as those in which at least one woman 12-49 years of age in the household spoke a native language. The prevalence of undernutrition (stunting, wasting and underweight) and anemia was compared between indigenous and nonindigenous children. Probability ratios (PR) were used to compare prevalences in indigeno us and non-indigenous children adjusting for socioeconomic status (SES) of the family and for other covariates. ResultsT he prevalences of stunting and underweight were greater in indigenous than in nonindigenous children.At the national level and in urban areas the prevalences were three times greater and in rural areas $\sim 2$ times greater $(p<0.05)$. No differences were found in the prevalence of wasting $(p>0.05)$. The prevalence of anemia in indigenous children was one third greater than in non-indigenous children at the national level $(p<0.05)$ and was between 30 and $60 \%$ greater in urban areas and in the regions studied $(p<0.05)$ but was not statistically significant $(p>0.05)$ in rural areas. These differences were reduced to about half when adjusting for SES but remained significantly
\end{abstract}

Rivera JA, Monterrubio EA, González-CossíoT, García-Feregrino R, García-Guerra A, Sepúlveda-Amor J. Estado nutricio de los niños indígenas menores de cinco años de edad en México: resultados de una encuesta nacional probabilística. Salud Publica Mex 2003;45 supl 4:S466-S476.

El texto completo en inglés de este artículo también está disponible en: http://www.insp.mx/salud/index.html

\section{Resumen}

Objetivo. Comparar las prevalencias de desnutrición y anemia en niños indígenas y no indígenas menores de cinco años de edad en el ámbito nacional, por región, por zonas urbanas y rurales, y evaluar en qué medida la condición socioeconomica de la familia predice las diferencias. Material y Métodos Se realizó una encuesta nacional probabilística en 1999 en México. Las familias indígenas fueron identificadas como aquellas en las cuales al menos una mujer entre 12 y 49 años de edad en el hogar hablara una lengua indígena. Las prevalencias de desnutrición (baja talla, emaciación y bajo peso) y anemia fueron comparadas entre niños indígenas y no indígenas. Se utilizaron razones de probabilidad para comparar prevalencias ajustando por las condiciones socioeconómicas de la familia y por otras variables. Resultados. Las prevalencias de baja talla y de bajo peso fueron mayores en indígenas que en no indígenas. En el ámbito nacional y en zonas urbanas las prevalencias fueron casi tres veces mayores, mientras que en zonas rurales fueron $\sim 2$ veces mayores $(p<0.05)$. No se encontraron diferencias en las prevalencias de emaciación ( $p>0.05$ ). La prevalencia de anemia en indígenas fue un tercio mayor que en no indígenas en el ámbito nacional $(p<0.05)$ y entre 30 y $60 \%$ mayor en áreas urbanas y en las regiones estudiadas $(p<0.05)$, pero no fue estadísticamente significativa en áreas rurales $(p>0.05)$. Estas diferencias se redujeron aproximadamente a la mitad al ajustar por las condiciones socioeconómicas,

(1) Centro de Investigación en N utrición y Salud, Instituto Nacional de Salud Pública, Cuernavaca, Morelos, México.

(2) Dirección General Instituto N acional de Salud Pública. Cuernavaca, Morelos, México.

Received on: A ugust 20, 2002 • Accepted on: July 25, 2003

Address reprint requests to: Juan A Rivera, MS, PhD, C entro de Investigación en N utrición y Salud, Instituto N acional de Salud Pública, Avenida Universidad No 655, colonia Santa María A huacatitlán, 62508 Cuernavaca, Morelos, México. E-mail:jrivera@.insp.mx 
higher in indigenous children $(p<0.05)$. Conclusions. Indigenous children have higher probabilities of stunting and underweight than non-indigeno us children.The differences are larger in urban areas and in higher socioeconomic geographic regions and are explained mostly by socioeco nomic factors. The overall difference in the probability of anemia is small, is higher only in urban relative to rural areas, and is explained to a lesser degree by socioeconomic factors. Policy and programs should be designed and implemented to reduce the dramatic differences in nutritional status between indigenous and non-indigenous children in Mexico. The English version of this paper is available too at: http:// www.insp.mx/salud/index.html

Key words: indigeno us children under five years of age; undernutrition; stunting; wasting; anemia;M exico pero continuaron siendo significativamente superiores en niños indígenas $(p<0.05)$. Conclusiones. Los niños indígenas tienen mayor probabilidad de presentar baja talla y bajo peso que los no indígenas. Las diferencias son mayores en áreas urbanas y en las regiones geográficas con mejores condiciones de vida, y se explican principalmente por factores socioeconómicos. La probabilidad de anemia entre poblaciones fue sólo modestamente mayor en zonas urbanas que en zonas rurales, y las diferencias son explicadas en menor grado por factores socioeconómicos. Se recomienda el diseño y aplicación de políticas y programas para eliminar las diferencias abismales en estado nutricio entre niños indígenas y no indígenas en México. El texto completo en inglés de este artículo también está disponible en: http:// www.insp.mx/salud/index.html

Palabras clave: niños indígenas menores de cinco años de edad; desnutrición; baja talla; emaciación; anemia; México
$\mathrm{T}$ he nutritional status of children $<5$ years of age is the result of the dietary intake and the health status which are determined by access to food, health services, sanitary conditions and education. These latter conditions are in turn caused by economic and social factors. Mexico has the largest indigenous population in the Americas. More than 6.7 million people in Mexico $(7.4 \%$ of the total population) were classified in 1995 as indigenous on the basis of the population 5 years of age and older who spoke a native language and children $<5$ years living in households where the family head or spouse was a speaker of any native language. ${ }^{1}$ The indigenous population in Mexico has lived under unfavorable socioeconomic conditions since the Mexican conquest by the Spaniards and continues to do so. Information available indicates that inequity between indigenous and non-indigenous population in Mexico is enormous. For example, while the infant mortality rate in Mexico was 35/1000 for the general population in 1990, the rate for the indigenous population that year was estimated at $55 / 1000 .^{2}$ A study that compared sociodemographic and health variables in predominantly indigenous municipalities (where $>40 \%$ of the population spoke a native language) vs predominantly non-indigenous municipalities ${ }^{3}$ reported that, in 1990, illiteracy rates were 3.1 times higher and the quality of the houses were much lower in predominantly indigenous municipalities. For example, while in predominantly indigenous municipalities only $54.3 \%$ of the houses had electricity, $38.1 \%$ had clean water supply and $15.7 \%$ had a sewage system, the corresponding figures for the national level were 87.5,79.4 and $63.6 \%$, respectively. As a result of poverty and in- adequate socioeconomic conditions and services, a higher prevalence of undernutrition is expected in the indigenous population. Community-based studies have documented the nutritional status of indigenous children in certain areas; however, to the best of our knowledge there is no information in the literature about the nutritional status of indigenous children in Mexico on the basis of national probabilistic samples. Information about the magnitude and distribution of undernutrition and anemia in indigenous children is crucial for planning interventions aimed at improving the nutrition and health of this underprivileged group. Therefore, the objectives of this paper are: 1) to compare the prevalence of undernutrition and anemia in indigenous and non-indigenous children $<5$ years of age at the national level, for urban and rural population, and by region and, 2) to evaluate the degree to which the socioeconomic condition of the family predicts the differences. Our hypotheses were that the prevalence of undernutrition is substantially higher in indigenous than in non-indigenous children and that a large part of the differences are accounted for by SES.

\section{Material and Methods}

Sample and design. Data were collected during the Second National Nutrition Survey, conducted by the National Institute of Public Health of Mexico between October 1998 and March 1999 in a national probabilistic sample of 17944 households in Mexico. ${ }^{4}$ The sampling methodology as well as the response rates are described in detail in an article published in this same issue. ${ }^{5}$ The resulting sample is representative of the 
national level, of urban and rural areas and of four geographic regions which include the following states: north (Baja California, Baja California Sur, Coahuila, Chihuahua, Durango, Nuevo León, Sonora, Tamaulipas), center (Aguascalientes, Colima, Guanajuato, Jalisco, México (excluding the municipalities that are part of the metropolitan area of Mexico City), Michoacán, Morelos, Nayarit, Querétaro, San Luis Potosí, Sinaloa, Zacatecas), Mexico City (including the Federal District and the municipalities that are part of the metropolitan area) and south (Campeche, Chiapas, Guerrero, Hidalgo, Oaxaca, Puebla, Quintana Roo, Tabasco, Tlaxcala, Veracruz, Yucatán). Information is available for a total of 8011 children $<5$ years of age.

Data collection. Weight and recumbent length (in children $<2$ years) and standing height (in children 2-4 years) were obtained using standard anthropometric methodology. ${ }^{4}$ Weight was measured to the nearest $10 \mathrm{~g}$ using an electronic scale (Tanita, Model 1583, Tokyo, Japan), length (to the nearest millimiter) using a locally made measuring board of $1.3 \mathrm{~m}$ and standing height using a stadiometer with capacity to measure up to $2 \mathrm{~m}$ and precision of $1 \mathrm{~mm}$ (Dyna-Top, model E-1, Mexico City, Mexico). The measurements were obtained by anthropometrists who were trained and standardized in all measurements using standard techniques. ${ }^{6,7}$ The birth date was reported by the mother and verified in a large proportion of children using birth certificates or vaccination cards, which are considered reliable documents in Mexico.

A blood sample was obtained from children 6-59 months of age by means of finger capillary puncture. The concentration of hemoglobin in the blood sample was measured using a portable photoreflectometer (hemocue). A drop of blood was placed into a cuvette in the hemocue which included dry reactants (sodium deoxycholate, sodium nitrite, and sodium azide) that converts the hemoglobin into metahemoglobin azide, which is measured at a wavelength of $565 \mathrm{~nm}$ in the portable photometer. The photometer was previously calibrated using a tray equipped with a red filter, calibrated with the international hemoglobin standard (Johns, WL and Lewis SM, 1992), according to the recommendation of the International Committee of Standardization in Hematology.

During the fieldwork, the photometers were calibrated twice weekly, registering the measurements of the control tray at the beginning and end of each day. If the variation was $>0.3 \mathrm{~g} / \mathrm{dl}$, the equipment was serviced. The intra-observer variability was evaluated in duplicate every 20 measurements. There were $74 \mathrm{du}$ plicate measurements with human blood and 60 measurements of the control tray analyzed per team. The average difference between duplicates was $0.03 \pm 0.99$ $\mathrm{g} / \mathrm{dl}, p=0.36$ for human blood and $-0.024 \pm 0.36 \mathrm{~g} / \mathrm{dl}$, $p=0.27$ for the duplicates of the reference cuvette. Values of hemoglobin $<4.5 \mathrm{~g} / \mathrm{dl}$ and $>18.5 \mathrm{~g} / \mathrm{dl}$ were excluded from the analysis. Children with hemoglobin values $<9 \mathrm{~g} / \mathrm{dl}$ were provided with ferrous sulfate treatment.

A question was asked to the informants of all families to identify those households in which at least one woman between 12 and 49 years of age spoke a native language. These households were classified as indigenous households, and children living in those households are referred to in the rest of the article as indigenous children. Likewise, children living in households classified as non-indigenous are referred to as non-indigenous children. Information about characteristics of the house, infrastructure and available services, and possession of selected household goods were obtained by interviewing the mothers of the participating children.

Consent for participation was obtained from the mother or informant in each household. The project was approved by the Human Subjects Committee of the National Institute of Public Health.

Data processing. Using the information about housing characteristics and possession of goods, an indicator of socioeconomic status (SES) was derived by the first component obtained by Principal Components Analysis..$^{8}$ Only variables with factor loadings $>0.7$ were maintained in the model. These included flooring material, availability of piped water, possession of refrigerator, washing machine and stove as well as the number of electric appliances in the household: radio, $\mathrm{TV}$, video player, telephone, and computer. The component explained $56 \%$ of the total variance. The resulting standardized factor scores were divided into deciles which were further used to construct four SES status categories: deciles 1, 2, 3-4 and 5-10.

Length/height and weight data were transformed to $\mathrm{z}$-scores using the WHO/NCHS/CDC reference data. ${ }^{9}$ Children were classified as underweight, stunted, and wasted when their z-scores were $<-2$ for weightfor-age, length/height-for-age and weight-for-length/ height, respectively. In the rest of the article, for simplicity, anthropometric indices are referred to as weightfor-age, height-for-age and weight-for-height, even when length rather than height was measured.

Anemia was defined as a concentration of hemoglobin $<11.0 \mathrm{~g} / \mathrm{dl}$ at sea level. ${ }^{10,11}$ The values for each location were adjusted according to their altitude above sea level. ${ }^{12}$ Altitude data were obtained from INEGI (the Mexican National Census Bureau). ${ }^{13}$

Data analyses. Relative risks (RR) of anemia and undernutrition for children in indigenous relative to nonindigenous families were estimated using probabilities 
ratios. Odds ratios $(\mathrm{OR})$ were not used as RR estimates because the prevalence of anemia, stunting and underweight is large and therefore OR are not adequate estimates of RR. Probability ratios (PR) were derived from group probabilities obtained from the logistic mod$\mathrm{els}^{14,15}$ and were adjusted through a method used for correcting odds ratios (OR) when prevalence is above $10 \%{ }^{16}$

The general methodological background on generalized linear model analyses of complex survey data was applied using the svy module of the STATA program for all analyses. ${ }^{17}$ In order to address the first objective, comparisons of anthropometric z-scores, hemoglobin concentration and the prevalences of undernutrition and anemia were made between indigenous and non-indigenous children at the national level, for families living in rural localities (population $<2500$ ) and urban localities (population $\geq 2500$ ) and for families living either in the south region or those living in any other region (north, center and metropolitan area). Data for the three latter regions were aggregated due to small sample sizes in each of them. Wald statistics for complex samples were used to test the differences between prevalences (chi-squared values) and the differences between continuous variables. ${ }^{17}$

The second objective was addressed through logistic regression models by evaluating changes in the probabilities of undernutrition (stunting and underweight) and anemia in indigenous and non-indigenous children and PRs in models that adjusted only for age and in models that adjusted for age and the socioeconomic status indicator. In addition, we tested other variables that could explain the remaining difference that was not explained by the SES indicator. The variables tested were: number of children in the family, mother's height, education of both parents (years of schooling and literacy), region and urban or rural residence.

The rationale behind the use of these variables was the following. Number of children may be an important determinant of nutritional status in poor families due to competition among siblings for scarce resources and care; mother's height was included in the model as a determinant of the body size of the child. The influence of maternal height may be genetic or environmental. For example, short mothers raised in healthy environments are likely to be short due to genetic factors which may be inherited by the child. In contrast short mothers who were raised in very poor environments may be short as a result of undernutrition and infection during their formative early life and may not be expressing their growth potential. Very short mothers tend to have lighter and shorter babies, which are in turn risk factors for undernutrition during early life. Also, since poverty is transmitted from one generation to the next, maternal short stature may be a risk factor for poverty and undernutrition of their siblings. The education of the parents was not included in our SES indicator; therefore it was included in the models because the mother's education has been shown to be associated with the nutritional status of their siblings. Also the education of the father is an important determinant of income generation, which may not be captured by our SES indicator. Since undernutrition and anemia differed by region and urban or rural residence, we included them in the model to test if variability not accounted for by the SES indicator was explained by these factors.

All $p$ values $<0.05$ were considered statistically significant. Analyses were performed using Stata (Stata Statistical Software, Release 6.0, Stata Corporation College Station, TX) and SPSS (SPSS for Windows, Release 10.0.0. Chicago, IL, SPSS Inc., 1999).

\section{Results}

Table I presents the number of children with information available on anemia and nutritional status for indigenous and non-indigenous children at the national level, by urban and rural areas, and by region. At the national level, a total of 7831 children had weight-forheight z-score information, a similar number of children had height-for-age (7 589) and weight-for-height (7 709) z-score information, representing between 93.8 and $96.7 \%$ of children $<5$ years of age for whom any information was available $(n=8011)$. The number of indigenous children with information on nutritional status was between 838 and 868 , about $11 \%$ of on children with z-score information.

Anemia status was available in 5372 children 1-4 years of age, representing $84.3 \%$ of children of that age group for whom any information is available $(n=6373)$. The number of indigenous children was $605,12.7 \%$ of all children with hemoglobin data.

The prevalence of stunting and underweight was almost three times greater in indigenous than in nonindigenous households at the national level and two to three times greater in the different areas and regions studied. All comparisons between indigenous and nonindigenous children were statistically significantly different $(p<0.05)$ for the prevalence of underweight and stunting. In contrast, wasting was not significantly different $(p>0.05)$ between indigenous and non-indigenous children (Table I).

The prevalence of anemia in indigenous children was one third greater than in non-indigenous chil- 


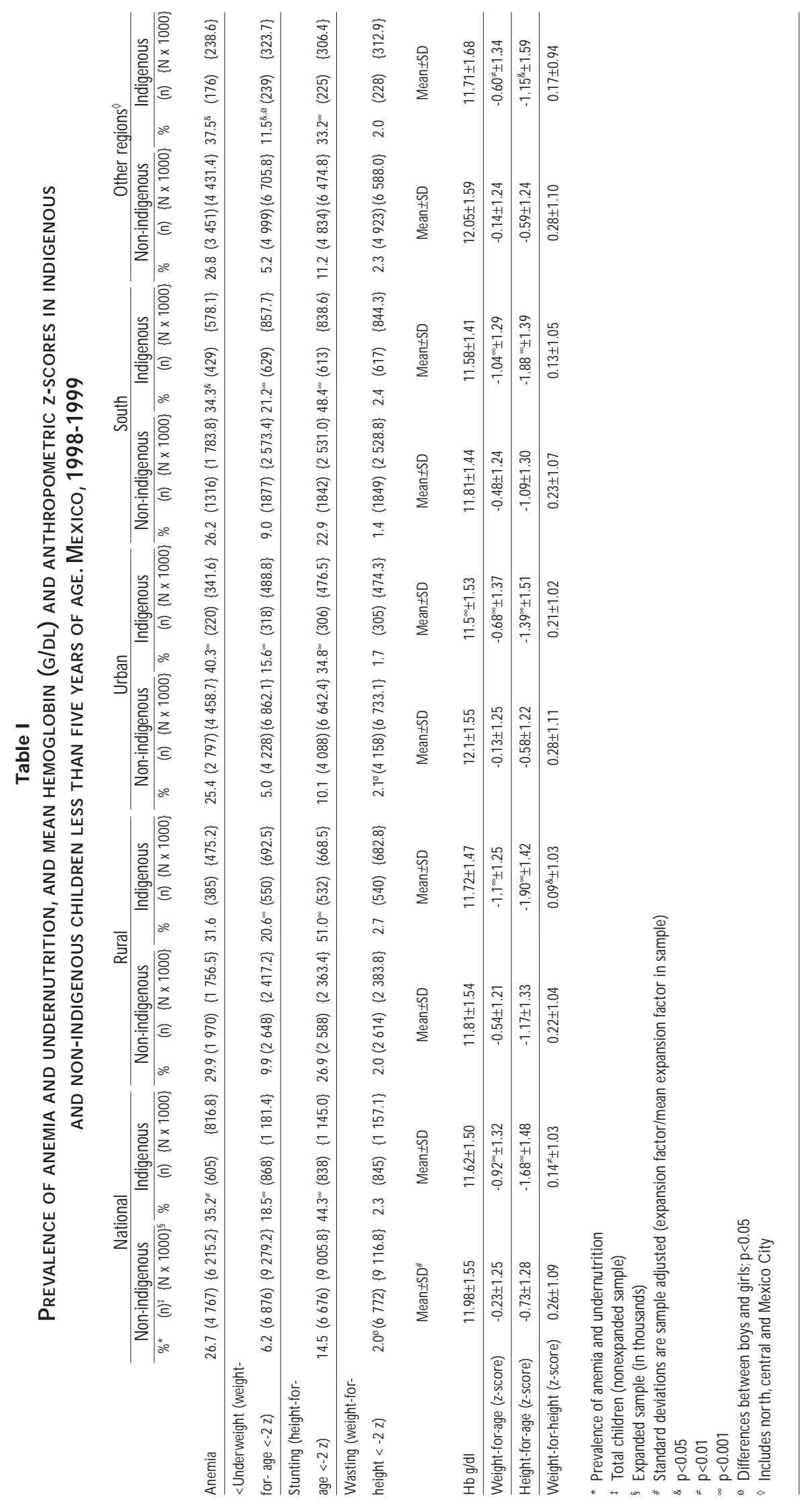


dren at the national level $(p<0.05)$ and was between 30 and $60 \%$ greater in urban areas, the south, and the three combined regions $(p<0.05)$. In contrast, the difference was smaller and not statistically significant $(p>0.05)$ in rural areas (Table I).

The differences in mean weight-for-age and height-for-age z-scores between indigenous and nonindigenous children were consistent with the results observed on the prevalence of undernutrition: lower $z$-score values occurred in indigenous children $(p<0.05)$ (Table I). Likewise, the differences between indigenous and non-indigenous children were small and biologically not important for weight-for-height z-scores, although some differences were statistically significant $(p<0.05)$ due to large sample sizes. Results for hemoglobin concentrations were also consistent with results for anemia: lower values were systematically found in indigenous children; however, most of the differences were not statistically significant $(p>0.05)$, except in urban areas $(p<0.05)$ (Table I).

The prevalence of anemia and undernutrition in boys and girls was compared in indigenous and nonindigenous families. Most differences between sexes were not statistically significant (not shown), except for the prevalence of wasting in non-indigenous children at the national level (boys $2.5 \%$ vs. girls $1.5 \%$ ) and in urban areas (boys $2.7 \%$ and girls $1.4 \%$ ), which were biologically unimportant, and the prevalence of underweight in the combination of three regions (boys 17.2\% vs. girls $6.0 \%$ ), which was not only statistically significant but also biologically important.

Figure 1 presents the frequency distribution of indigenous and non-indigenous children by SES categories. Deciles 3 and 4 and 5 to 10 were collapsed in order to achieve reasonable sample sizes in the indigenous population. An excess proportion of indigenous children, relative to non-indigenous children were found in the three lower categories, along with a smaller proportion in the upper category, indicating poorer socioeconomic situation in indigenous relative to nonindigenous children.

The prevalence of underweight is higher in indigenous than non-indigenous children only for the two lower SES categories (Figure 2 and Table II). The prevalence of stunting is higher in indigenous than nonindigenous children for all SES categories $(p<0.05)$, but the differences are larger in the lower categories and decrease as SES improves (Figure 2 and Table II). No differences in prevalence of wasting were observed between indigenous and non-indigenous children in any of the SES categories (Table II).

The patterns of anemia prevalence by SES categories were different in indigenous and non-indigenous

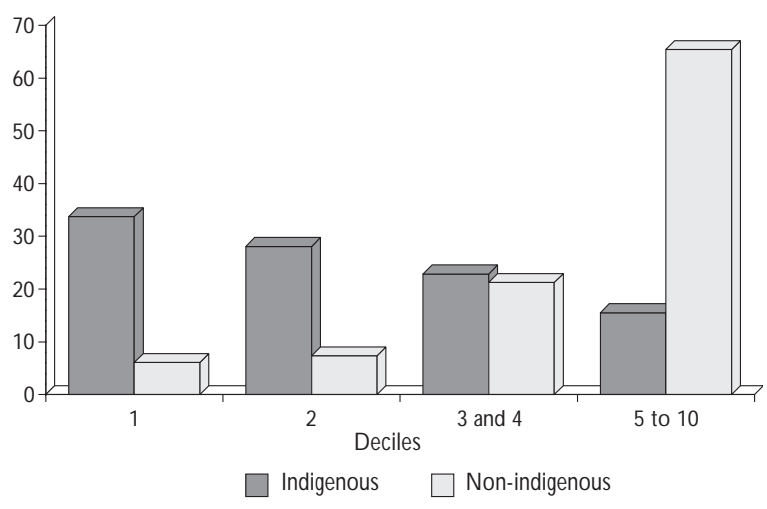

Figure 1. Frequency distribution of Indigenous and NON-INDIGENOUS CHILDREN YOUNGER THAN FIVE YEARS OF AGE BY SOCIO-ECONOMIC STATUS DECILES. MEXICO, 19981999

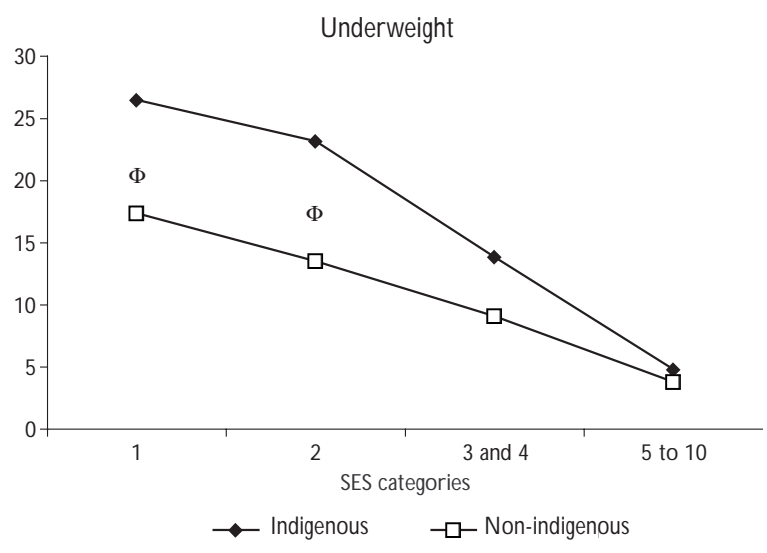

$\Phi P<0.05$ between indigenous and non-indigenous children

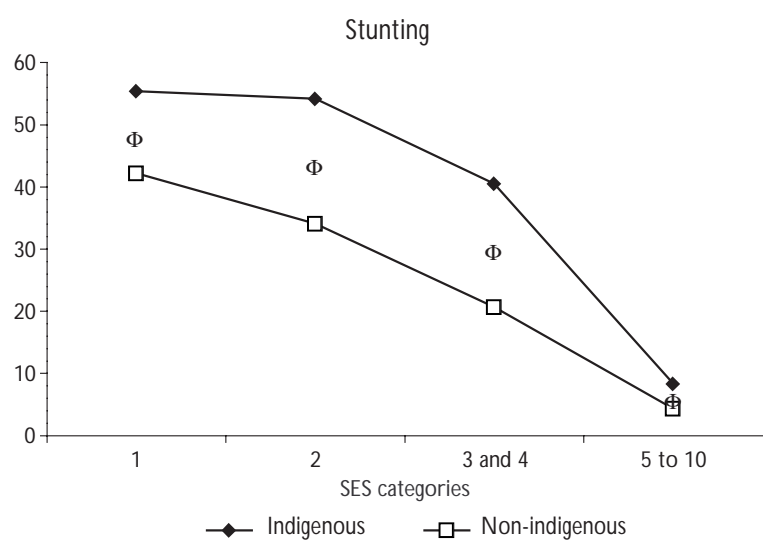

Figure 2. Prevalences of Underweight and stunting IN INDIGENOUS AND NON-INDIGENOUS CHILDREN LESS THAN FIVE YEAR OF AGE BY SOCIO-ECONOMIC STATUS CATEGORIES. MEXICO, 1998-1999 
children. Non-indigenous children had a similar prevalence of anemia (around 30\%) in the three lower SES categories (deciles 1-4) and dropped to $24.5 \%$ in the upper SES category (deciles 5-10). In contrast, the prevalence in indigenous children increased from $24.2 \%$ in the low SES category ( $1^{\text {st }}$ decile), to about $38 \%$ in the two intermediate SES categories ( $2^{\text {nd }}$ to $4^{\text {th }}$ deciles) and to $43.8 \%$ in the high category ( $5^{\text {th }}$ to $10^{\text {th }}$ deciles). The differences in the prevalence of anemia between indig- enous and non-indigenous children was not statistically significant for the three lower SES categories, but it was almost 20 percent points higher in indigenous children (statistically significant) in the higher SES category (Table II).

So far, all differences in prevalence presented are not adjusted for other variables. Table III presents the results of logistic regression models which were performed to estimate the probability of underweight,

Table II

Prevalence of anemia and undernutrition in Indigenous and NON-INDigenous ChILDRen Younger THAN FIVE YEARS OF AGE ACCORDING TO SOCIOECONOMIC CATEgories. MEXICO, 1998-1999

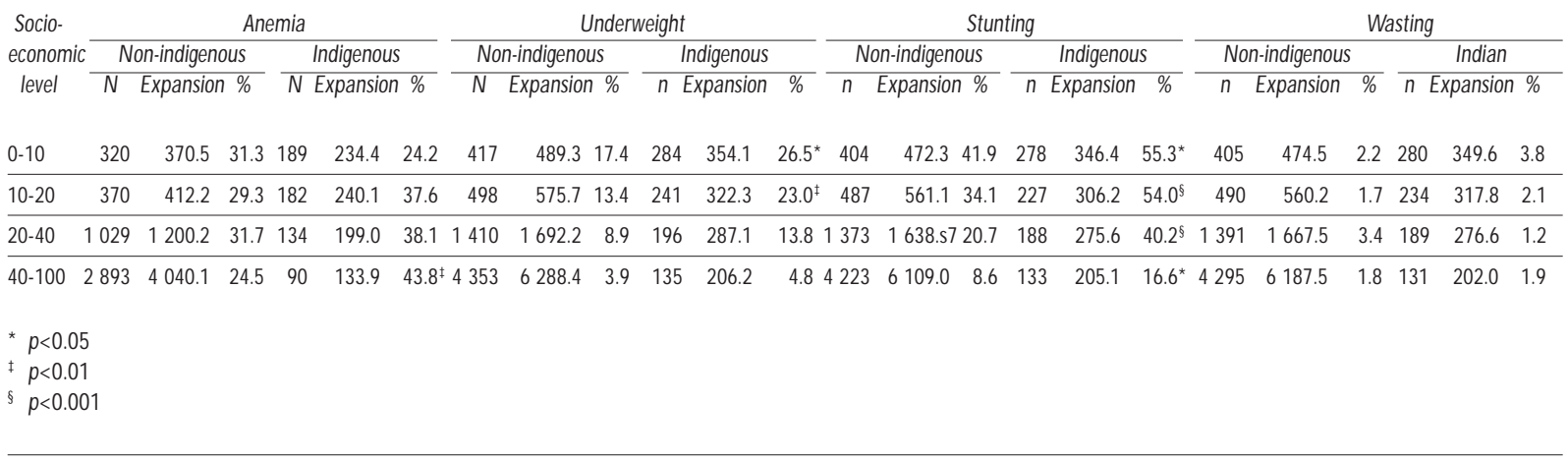

Table III

ADJUSTED AND UNADJUSTED PROBABILITY RATIOS FOR ANEMIA AND UNDERNUTRITION OF INDIGENOUS RELATIVE TO NON-INDIGENOUS CHILDREN YOUNGER THAN FIVE YEARS OF AGE. MEXICO, 1998-1999

Dependent variables

N

Non-indigenous $P_{0}$ Indigenous $P_{1}$

Probability Ratios

Stunting

\begin{tabular}{lrrr} 
Adjusted for age of children* & 6866 & 0.16 & 0.48 \\
\hline Adjusted for age of children and socioeconomic level ${ }^{\ddagger}$ & 0.15 & 0.28 & $1.83(1.49,2.21)$ \\
\hline Adjusted for all variables & 0.16 & 0.29
\end{tabular}

Underweight

\begin{tabular}{llll} 
Adjusted for age of children* & 7079 & 0.173 & $2.98(2.27,3.66)$ \\
\hline Adjusted for age of children* and socioeconomic level & 0.054 & 0.081 \\
\hline Adjusted for all variables & 0.053 & 0.077 & $1.45(1.11,1.87)$
\end{tabular}

Anemia

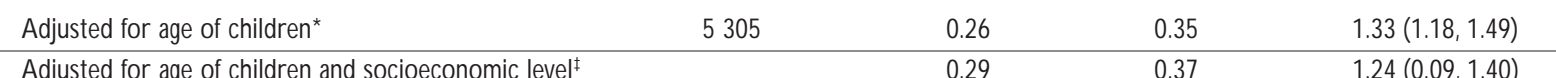

* Age of children, age of children to square

₹ A ge of children, age of children to square, socioeconomic level, socioeconomic level to square

$\S$ A ge of children, age of children to square, socioeconomic level, socioeconomic level to square, number of children in the family, and place of residence (urban or rural and region)

\# Age of children, age of children to square, socioeconomic level, number of children in the family 
stunting and anemia in indigenous and non-indigenous children adjusting only for age, adjusting for age and SES, and adjusting for age, SES and a number of covariates. Adjusted probabilities and PRs are presented. The number of cases for each outcome variable was kept constant across models with different adjustments.

As expected, age was statistically associated with the three outcome variables in a quadratic fashion (Table III). Maternal height was also statistically associated with the three outcome variables studied, in the models that adjusted for all the covariates. However, maternal height data were missing in a substantial number of cases $(742,776$, and 858 in the models for stunting, underweight and anemia, respectively), representing between $11 \%$ and $16 \%$ of the total cases. Since the predicted probabilities and PR values for the models with or without maternal height did not differ, we choose to present the models without maternal height (Table III) in order to avoid dropping so many cases with missing values for this variable.

Estimated probabilities for stunting and underweight were very similar for the three logistic models performed (adjusted for age, adjusted for age and SES, and adjusted for age, SES and covariates) in non-indigenous children. In contrast, in indigenous children probabilities drop substantially when adjusted for SES status. As a result PRs drop considerably when adjusted for SES status. The PRs were 3.4 for stunting and 2.9 for underweight in the age-adjusted model (Table III); dropped to 1.83 for stunting ( $50 \%$ decrease) and 1.48 for underweight ( $50 \%$ decrease) when adjusting for SES. Further adjustment produced virtually no change in the PR values (1.81 for stunting and 1.45 for underweight (Table III). All the PR for underweight and stunting, including those corresponding to the model adjusted for SES and the covariates, were statistically significant.

The PRs for anemia were much lower than the values found for undernutrition. The age-adjusted PR was $1.33(p<0.05)$ and dropped to 1.24 when adjusting for socioeconomic status $(p>0.05)$. No other covariates besides age and socioeconomic status were statistically significant $(p>0.05)$.

Since no differences were found in the prevalence of wasting between indigenous and non-indigenous children, this indicator of nutritional status was excluded from the logistic analysis.

\section{Discussion}

In Mexico, the probability of stunting and underweight in indigenous children is almost three times higher than in non-indigenous children (Table I). As we suspected, an important part of the differences in the probabilities of underweight and stunting between indigenous and non-indigenous children is explained by our indicator of SES conditions, as revealed by the drop in about $50 \%$ in PR values for stunting and underweight when adjusting for SES. Other variables such as number of children in the household and place of residence (region, and rural and urban areas) explain an additional smaller part of the differences, but the remaining differences are still statistically significant, suggesting other important explanatory factors exist (Tables III). In contrast, the differences in the prevalence of wasting between indigenous and non-indigenous children are small and are generally not statistically significant (Table I).

The magnitude of the differences in stunting and underweight between indigenous and non-indigenous children is remarkable not only at the national level ( $\sim 3$ times) but also in the rural areas and the south, the poorest regions ( $\sim 2$ times), and in urban areas, where the difference is more than three times. In the three regions other than the south, the difference is almost three times for stunting and over two times for underweight. The absolute differences in prevalence of stunting between indigenous and non-indigenous children are about 30 prevalence points at the national level and are not different between urban and rural areas or by regions, ranging between 22 and 25 prevalence points.

The prevalence of anemia is also higher in indigenous children, but the difference is more modest: about $30 \%$ at the national level. The differences are slightly larger in the three regions excluding the south $(\sim 40 \%)$ than in the south $(\sim 30 \%)$ and are much higher in urban $(\sim 60 \%)$ than in rural areas $(\sim 6 \%)$. The absolute differences in anemia are also more modest (8 percentage, points at national level), but are different between rural ( $\sim 2$ percentage, points) and urban $(\sim 15$ percentage, points) areas and between the south ( $\sim 8$ percentage, points) and other regions ( $\sim 11$ percentage, points).

The data come from a national probabilistic sample, and although the survey was not designed to be representative of the indigenous population of Mexico, $11 \%$ of the households with children $<5$ years of age in the sample were classified as indigenous. The number of indigenous households was large enough to provide valid estimates of the prevalence of stunting, underweight, and anemia in indigenous children at the national level $(n=841)$, in urban $(n=306)$ and rural $(n=535)$ areas, in the south region $(n=616)$, and in the three other regions excluding the south $(n=225)$, but not for each one of these three individually regions. The variable used to identify indigenous families underestimates the total number of families where an 
adult speaks a native language because it is based on women 12-49 years of age who speak a native language; therefore, if older women ( $>49$ years of age) or any men spoke a native language but none of the women 12-49 years did, the family was classified as non-indigenous, despite the fact that an adult spoke a native language. This misclassification error may affect some estimates, particularly in non-indigenous children, as will be discussed later; however, the classification system identifies a group that is very likely to maintain an indigenous culture, beliefs and values, given that women at reproductive age, the basis for the classification, are usually those who make choices related to feeding practices, health care and child-rearing patterns.

As mentioned earlier, most of the misclassification errors of our system are families with a native language speaking adults other than women $12-49$ years of age who were classified as non-indigenous. Therefore, the estimates of prevalence in families classified by us as non-indigenous may be biased towards values similar to those found in indigenous families, because indigenous families are included in the estimates. However, given the relatively low proportion of indigenous families in Mexico, and the fact that our system classified as indigenous families a proportion that is very similar to independent estimates of the indigenous population in Mexico, we conclude that the magnitude of the possible bias must be small and that the bias, if any, tends to underestimate the differences between indigenous and non-indigenous population.

The low proportion of children classified as wasted in Mexico is close to the expected proportion of children with $<-2$ z-scores in a healthy population. Therefore, a large proportion of children classified as wasted are probably false positives. This may explain the small difference in wasting between indigenous and non-indigenous children and confirm that even among indigenous children, one of the poorest groups in Mexico, wasting is relatively low, while the prevalence of stunting is high. Underweight, a nonspecific index that reflects both wasting and stunting, follows the general patterns of the prevalence of stunting in Mexico, because the prevalence of wasting is low. Therefore, the rest of the discussion will focus on stunting with some reference to underweight.

The striking differences in stunting between indigenous and non-indigenous children result from the large differences in living conditions between the two populations as shown in Figure 1. Indigenouss are among the poorest populations in Mexico; almost 62\% of the indigenous population lie in the two lowest SES deciles, while less than $15 \%$ of the non-indigenous population are located in those deciles (Figure1). There- fore, indigenous children are more exposed than nonindigenous children to poor diets and infections which are the two direct causes of undernutrition. When socioeconomic status was adjusted for in the logistic regression models, the PR for stunting dropped substantially (from 3.40 to 1.83), indicating that a sizeable part of the differences are explained by our SES indicator (an indicator of housing quality and services). When other variables were included in the model, the relative risk was reduced slightly, but was still important (1.80) and remained statistically significant, indicating that other factors not included in the model may explain the differences. Among the possible factors are genetic differences between indigenous and non-indigenous children, differences in child-rearing practices, including child-feeding behaviors and hygiene practices, differences in the sanitary conditions and health services and other socioeconomic factors not captured by the variables included in the model. Further evidence about the importance of socioeconomic status for explaining the differences in stunting between indigenous and non-indigenous children is shown in Figure 2 . The relatively small proportion of indigenous children living in the upper six SES deciles, have a prevalence of underweight not statistically different from non-indigenous children.

It is unlikely that most of the remaining differences in stunting between indigenous and non-indigenous children, after adjusting for socioeconomic status and other factors in the models, are due to genetic factors as has been shown in the literature, ${ }^{18-21}$ but we can not rule out that possibility with the data available. However, it is likely that cultural dissimilarities, resulting in differences in child-feeding practices and hygiene behaviors, or sanitary and other socioeconomic differences not captured by the variables employed, explain the remaining higher risk of stunting in indigenous children. Nonetheless, these conclusions are speculative and merit further research.

The larger relative difference in the prevalence of stunting between indigenous and non-indigenous children in higher socioeconomic urban areas, relative to poorer rural areas, is not explained by absolute differences, which are similar. Instead, the relative differences are due to the lower prevalence of stunting in urban areas and in the three regions other than the south both in non-indigenous and indigenous children, rendering the differences of similar absolute magnitude larger in relative terms. In other words, although the prevalence of stunting is higher in rural areas and the south for both indigenous and non-indigenous children, the relative gap between indigenous and nonindigenous children is larger in urban than in rural 
areas and in the more developed regions (north, Mexico City, center) than in the south.

The differences in the prevalence of anemia between indigenous and non-indigenous children are different from the patterns shown for stunting. The differences are relatively modest, except in urban areas. Another difference between anemia and stunting is that the prevalence of anemia is higher in indigenous children only in the highest SES category (the upper six deciles) but not in the lowest four deciles.

The results suggest that, as opposed to stunting which is highly associated with socioeconomic factors across all socioeconomic values in a linear trend for both indigenous and non-indigenous children (Figure 2), the association between socioeconomic factors and anemia shows a threshold relationship in non-indigenous population (Figure 3), in which the prevalence does not vary across the four lower socioeconomic conditions deciles, and drop at the highest socioeconomic conditions category (the upper six deciles). The relationship between anemia and SES in indigenous children is intriguing, because it shows an increasing trend with SES. Prevalence is not different between indigenous and non-indigenous children across the three lower SES categories, but is higher in indigenous children at the highest SES category. The increasing trend in the association between socioeconomic conditions and anemia in indigenous children is difficult to explain and merits further investigation.

The dramatic differences in nutritional status between indigenous and non-indigenous children found in our study call for immediate action to eliminate the gap in undernutrition prevalence between indigenous and non-indigenous children. Public nutrition programs aimed at reducing the prevalence of undernutrition should have indigenous children as one of the priority target groups. Current efforts to improve the nutritional status of indigenous children should be expanded and strengthened substantially in order to achieve an impact in the short term. The importance of SES factors in explaining the higher prevalences of undernutrition in indigenous children indicate the need to couple health and nutrition interventions with actions aimed at enhancing the living conditions of the indigenous population, as a necessary strategy for improving their nutritional status. The results also identify the need to conduct both qualitative as well as epidemiologic research about factors that may explain the differences not accounted for the variables in our models, such as access to health care, sanitary conditions and differences in child feeding and rearing practices. The result of the proposed research should be incorporated into planning interventions for improving the nutrition of indigenous children.

We conclude that indigenous children have a higher probability of stunting and anemia than non-indigenous children. The higher probability of stunting is large and explained predominantly by socioeconomic factors. The differences in probability are relatively larger in urban areas and in regions with better economic conditions. The higher probability of anemia is modest, is higher only in urban relative to rural areas, and is explained only to some extent by socioeconomic factors, and the difference is found only among the higher socioeconomic levels. Finally, policy and programs should be designed and implemented to eliminate the gap in nutritional status between indigenous and non-indigenous children in Mexico.

\section{References}

1. Instituto $\mathrm{N}$ acional de Estadística, G eografía e Informática. Resultados definitivos del Conteo General de Población y Vivienda, 1995. México, DF: IN EGI, 1997.

2. Fernández P. La mortalidad infantil indígena en 1990: una estimación a través de los municipios predominantemente indígenas. México, DF: SSA-CEPS, 1992.

3. Bronfman M. La salud de los pueblos indígenas. U na conquista impostergable. México, D F:Secretaría de Salud, 1994; C uadernos de Salud.

4. Rivera-D ommarco J, Shamah-Levy T,Villalpando-Hernández S, González-de Cossío T, Hernández-Prado B, Sepúlveda J. Encuesta $N$ acional de $N$ utrición 1999. Estado nutricio en niños y mujeres en México. Cuernavaca, Morelos, México: Instituto N acional de Salud Pública, 2001.

5. Resano-Pérez E, Méndez-Ramírez I, Shamah-Levy T, Rivera-D ommarco JA, Sepúlveda J. Methods of the N ational N utrition Survey (1999): Results of a N ational Probabilistic Survey. Salud Publica Mex (in press). 6. Lohman T, Roche A, Martorell R. Anthropometric standarization reference manual. C hamplaign, (IL): Human Kinetics, 1988.

7. Habicht JP. Estandarización de métodos epidemiológicos cuantitativos sobre el terreno (Standardization of anthropometric methods in the field). Bull Pan Am Health 0 rgan 1974;76:375-384.

8. Hair JF,Anderson RE, Tatham RL, Black W C. Multivariate data analysis with reading. $3^{\text {rd }}$ edition. N ew York (N Y): Macmillan Publishing, 1992. 9.W orld $\mathrm{H}$ ealth $\mathrm{O}$ rganization. Measurement of nutritional impact. Geneva:W HO,1979.

10.W orld $\mathrm{H}$ ealth 0 rganization. The prevalence of anemia in women:A tabulation of available information. 2nd edition, Geneva:W HO, 1992. 11. International N utritional Anemia C onsultative G roup.W ashington, DC: ILSI Human N utrition Institute. Guidelines for the Control of Maternal N utritional Anemia.A report of the International N utritional Anemia Consultative Group (IN AG), 1989.

12. Ruiz-Argüelles $G$, Llorente-Peters A. Predicción algebraica de parámetros de serie roja de adultos sanos residentes en alturas de 0 a 2670 metros. Rev Invest Clin 1981;33:191-193. 
13. Instituto N acional de Estadística, Geografía e Informática. Base de datos de la Encuesta y Resultados Complementarios. Estados Unidos Mexicanos. Conteo de Población y Vivienda 1995 [Producto en Disco Compacto]. A guascalientes, A guacalientes, México, DF: IN EGI, 1997.

14. Hosmer DW, Lemeshow MS.A pplied logistic regression. N ew York (N Y): John W iley \& Sons, 1989.

15. Brant R. D igesting logistic regression results. Am Stat 1996;50(2):117-119.

16. Jun Zhang Kai F,Yu F.A method of correcting the odds ratio in cohort studies of common outcomes. JAMA 1998;280:1690-1691. 17. Stata Corporation. Stata Reference Manual Release 7. College Station (TX): Stata Press, 1985-2001;Volumes 1-4.
18. Habicht JP, Martorell R, Yarbrough C, Malina RM, Klein R. H eight and weight standards for preschool children: How relevant are ethnic differences in growth potential? Lancet 1974;1:611-615.

19. Martorell R. N otes on the history of nutritional anthropometry. Fed Proc 1981;40:2572-2576.

20. Amigo H, Erazo M, Bustos P. Estaturas de padres e hijos chilenos de diferente etnia y vulnerabilidad social. Salud Publica Mex 2000;42:

504-510.

21. Bustos $P$, A migo H, Muñoz SR, Martorell R. Growth in indigenous and non-indigenous Chilean schoolchildren from 3 poverty strata. Am J Public Health 2001;91:1645-1649. 